ical column (Lichrosphere RP8, $5 \mu \mathrm{m}, 4 \times 125 \mathrm{~mm}$. UV detection at $210 \mathrm{~nm})$. Isocratic elution with acidic $(0.1 \%$ phosphoric acid) aqueous acetonitrile $(54 \%)$ gave a net retention volume of $2.9 \mathrm{~mL}$.

[9] Column Lichrosphere RP8, $5 \mu \mathrm{M}, 4 \times 125 \mathrm{~mm}$, UV detection at 210 and $254 \mathrm{~nm}$. Elution (flow rate $1 \mathrm{~mL}$ per $\mathrm{min}$ ) proceeded with acidic $(0.1 \%$ phosphoric acid) aqueous eluent (54\% acetronitrile) $3 \mathrm{~min}$ isocratically with a subsequent linear gradient over $7 \mathrm{~min}$ to $90 \%$ acetonitrile and finally isocratic elution with $90 \%$ aqueous acetonitrile.

[10] Column Lichrosphere RP8, $5 \mu \mathrm{M}, 16 \times 250 \mathrm{~mm}$, UV detection at $340 \mathrm{~nm}$. Eluent: acidic $(0.1 \%$ phosphoric acid) aqueous solvent; linear gradient from 45 to $55 \%$ acetonitrile over $5 \mathrm{~min}$ followed by gradient elution from 55 to $90 \%$ acetonitrile over 10 min and finally isocratic elution with $90 \%$ aqueous acetonitrile; flow rate $7 \mathrm{~mL}$ per min.

[11] UV/VIS (methanol): $\lambda_{\max }[\mathrm{nm}](\log \varepsilon)=239(4.28), 330(4.36)$, see H. A. B. Linke, D. Pramer, Z. Naturforschung. B 1969, 24, 997-999. ${ }^{1} \mathrm{H}$ NMR ([D $]$ acetone): $\delta=7.97(\mathrm{dd}, 2 \mathrm{H}, J=2.2,8.6 \mathrm{~Hz}), 8.12(\mathrm{~d}, 2 \mathrm{H}$, $J=2.2 \mathrm{~Hz}$, $18.85(\mathrm{~d}, 2 \mathrm{H}, J=8.6 \mathrm{~Hz}$ ) see also M. T. S. Hsia, C. F. Burant, J. Assoc. Off. Anal. Chem. 1979, 62, 746-750. These data agree with those of the trans isomer.

[12] HRMS: $m / z 286.9675$ (calculated for ${ }^{12} \mathrm{C}_{12}{ }^{1} \mathrm{H}_{8}^{35} \mathrm{Cl}_{3}^{14} \mathrm{~N}^{16} \mathrm{O}: m / z$ 286.9671) MS (70 cV): $m / z(\%) 294(2), 293(7), 292(18), 291(38), 290(53), 289(100)$, $288(59), 287(96), 255(1), 254(2), 253(5), 252(4), 251(6), 220(15), 219$ (33), $218(46), 217(75)$.

[13] ${ }^{1} \mathrm{H}$ NMR ([D $]$ ]acetone): $\delta=6.76(\mathrm{dd}, 1 \mathrm{H}, J=2.7,8.8 \mathrm{~Hz}), 6.86(\mathrm{dd}, 1 \mathrm{H}$, $J=2.7,8.8 \mathrm{~Hz}), 6.90(\mathrm{~d}, 1 \mathrm{H}, J=2.7 \mathrm{~Hz}), 7.00(\mathrm{~d}, 1 \mathrm{H}, J=2.7 \mathrm{~Hz}), 7.25$ (d, $1 \mathrm{H}, J=8.6 \mathrm{~Hz}), 7.30\left(\mathrm{~d}, 1 \mathrm{H}, J=8.6 \mathrm{~Hz}\right.$ ); UV/VIS (methanol): $\lambda_{\max }$ $[\mathrm{nm}](\log \varepsilon)=212(4.82), 281(4.52), 493(1.90)$

[14] K. E. Simmons, R. D. Minard, A. J. Freyer, J.-M. Bollag, Int. J. Environ. Anal. Chem. 1986, 26, 209-227; K. E. Simmons, R. D. Minard, J.M. Bollag, Environ. Sci. Technol. 1987, 21, 999-1003.

[15] B. C. Saunders, A. G. Holmes-Siedle, B. P. Stark, Peroxidase, Butterworth, Washington D. C., 1964, p. 14.

[16] H. B. Lieb, C. C. Still, Plant Physiol. 1969, 44, 1672-1673; L, M. Bordeleau, R. Bartha, Can. J. Microbiol. 1972, 18, 1873-1882.

[17] A. Svenson, L.-O. Kjeller, C. Rappe, Environ. Sci. Technol. 1989, 23, 900902; L. G. Öberg, B. Glas, S. E. Swanson, C. Rappe, K. G. Paul, Arch. Environ. Contam. Toxicol. 1990, 19, 930-938; H.-C. Wagnes, K.-W. Schramm, O. Hutzinger, Z. Umweltchem. Ökotoxicol. 1990, 2, 63-65.

\section{First Example of a Chlorophin from an Unexpected Oxidative Ring-Opening of an (Octadehydrocorrinato)nickel(II) Salt**}

\section{By Chi K. Chang,* Weishih Wu, Shuenn-Shing Chern, and Shie-Ming Peng*}

The presence of vic-dihydroxychlorin or its lactone as the heme prosthetic group in d-type cytochromes has recently been elucidated. ${ }^{[1]}$ The diol structure raises the possibility that these green heme compounds might be derived biosynthetically from epoxidation of the porphyrin $\beta-\beta$ double bond. In pursuit of such an epoxychlorin, we examined the green compound 1 first reported by Johnson and co-workers, ${ }^{[2]}$ who obtained it from air oxidation of (1,19-dimethyloctadehydrocorrinato)nickel(II) chloride (2). Until very recently ${ }^{[3]}$ this was the only known example of epoxychlorin. We discovered that structure 1 is nonexistent; this compound is in fact a totally unexpected and unprecedented tetraaza macrocycle consisting of only three pyrrole units with the

[*] Prof. C. K. Chang, Dr. W. Wu

Department of Chemistry

Michigan State University

East Lansing, MI 48824 (USA)

Prof. S.-M. Peng, S.-S. Chern

Department of Chemistry

National Taiwan University

Taipei (Taiwan)

[**] This research was supported by the National Institutes of Health (GM 34468 and GM 36520) at Michigan State University and by the National Science Councit of the Republic of China (NSC80-0208-M002-58). CKC thanks the NSC and National Taiwan University for a Visiting Professorship. fourth pyrrole torn apart and reassembled into an exocyclic furan ring. This structure is so unusual that it represents a new member in the porphyrin family.

Following Johnson's procedure, ${ }^{[2]} 2$ was stirred in $o$ dichlorobenzene at $150-160^{\circ} \mathrm{C}$ in air for about 20 minutes to give a green pigment as the major product $(34 \%$ ) along with a nickel porphyrin $3(15 \%)$. Although the mass spec-
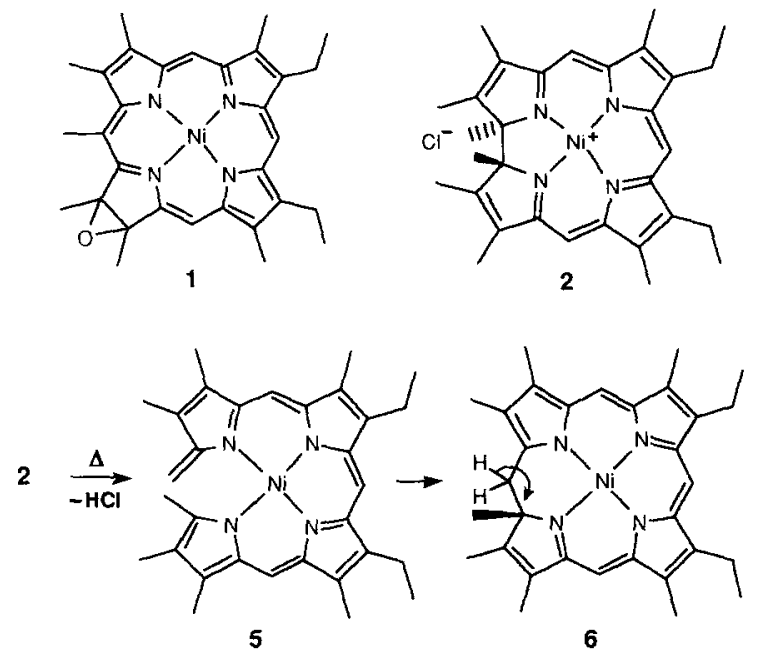

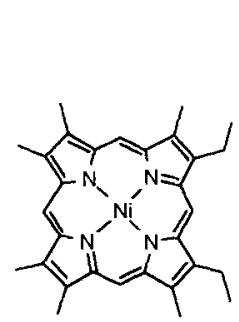

3
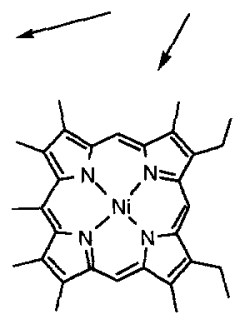

4

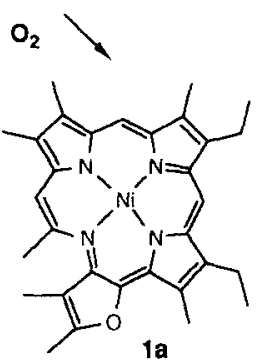

1 a<smiles>CCc1[nH]c(C(=O)C(=N/C(C)=C\c2[nH]c(/C=c3\[nH]/c(=C\c4[nH]c(C)c(CC)c4C)c(C)c3C)c(C)c2C)/C(C)=C(\C)O)c(C)c1C</smiles>

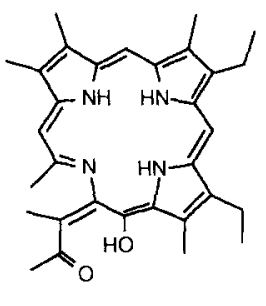

trum $(m / z 536)$ of the green product ${ }^{14]}$ showed the addition of one oxygen atom to 2 , and its absorption spectrum resembled those of metallochlorins, the chemical reactivities were incompatible with the suggested epoxide structure. For example, it failed to react with methyllithium and could not be reduced by $\mathrm{LiAlH}_{4}$. Since NMR analyses were unable to determine where the oxygen atom had attached, we turned to $\mathrm{X}$-ray diffraction. Crystallization of this compound from a series of solvent systems almost always gave twinned crystals unsuitable for X-ray study. A single crystal was finally obtained from diethyl ether. From its structure (Fig. ${ }^{[5]}$ ) one can readily appreciate what complicated rearrangements have taken place: The corrin frame has expanded and one angular methyl group has become a methine bridge. The pyrrole $\alpha-\beta$ bond adjacent to the other angular methyl group was broken, and the vinylic appendage of the broken pyrrole turned through $180^{\circ}$ to reattach itself to the macrocycle via an oxide. The resultant structure is a fully conjugat- 
ed $18 \pi$ chlorin-like skeleton with only three pyrrolic components. In order to highlight the relationship with the parent chlorin we propose the name "furochlorophin" for the new compound, since "chlorophin" has been suggested ${ }^{[6]}$ for the hitherto unknown tripyrryltetraaza macrocycle. The crystal structure showed normal carbon-carbon and metal-nitrogen bond lengths typical of nickel porphyrinoids. ${ }^{[7]}$ The nickel ion is essentially coplanar with the four nitrogens but the molecule deviates noticeably from planarity, for example, by $0.86 \AA$ at $\mathrm{C} 15,0.57 \AA$ at $\mathrm{C} 16$ and particularly for the furan ring by $-0.74 \AA$ at $\mathrm{C} 17,-1.58 \AA$ at $\mathrm{C} 18,-1.93 \AA$ at $\mathrm{C} 19$, and $-1.38 \AA$ at $\mathrm{O}$. The contracted core of Ni porphyrins caused by short $\mathrm{N}-\mathrm{Ni}$ bonds often results in a warped ring, but nonplanarity in this molecule is additionally attributed to the repulsion between $\mathrm{C} 29$ and C 30 methyl groups.

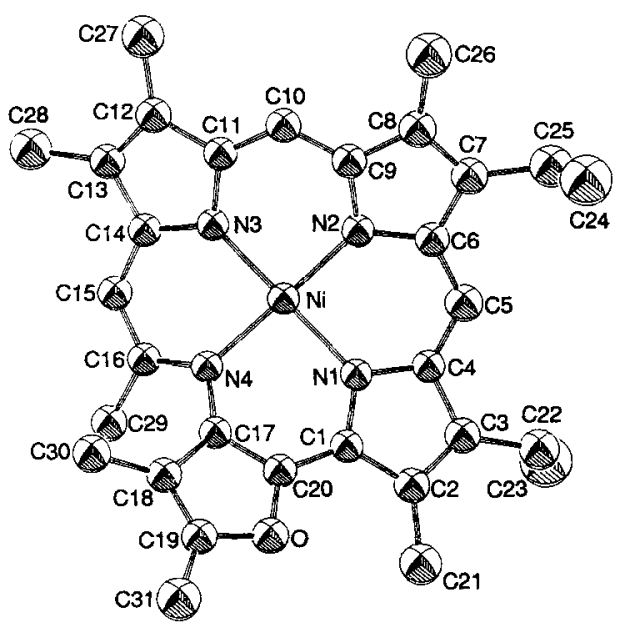

Fig. 1. Structure of $1 \mathrm{a}$ in the crystal. Selected bond distances $[\AA]: \mathrm{Ni}-\mathrm{N}(1)$ 1.945, Ni-N(2) 1.902, Ni-N(3) 1.901, Ni-N(4) 1.908, N(1)-C(1) 1.355, N(4)C(17) $1.377, \mathrm{~N}(4)-\mathrm{C}(16) 1.372, \mathrm{C}(17)-\mathrm{C}(20) 1.372, \mathrm{C}(17)-\mathrm{C}(18) 1.432, \mathrm{C}(20)-\mathrm{O}$ $1.377, \mathrm{C}(19)-\mathrm{O} 1.381$

The initial step proposed for the thermolysis of $2^{[2]}$ is a proton abstraction from one of the angular methyl groups by the anion to give the ring fission product 5 , which then cyclizes to 6 . The oxidation of 6 could give rise to porphyrin 3 and $\mathbf{4}$, depending on the nature of the original anion. In the present case the fission of the pyrrole $\alpha-\beta$ bond competes favorably with the cleavage of the angular methyl group. As often the case, the reaction mechanism associated with air oxidation is difficult to establish. No concrete mechanism can be offered at this time for the formation of the furan ring. Possibly an oxophlorin-like intermediate is formed first at C 20 , as this meso position is particularly susceptible to oxidation. ${ }^{[8]}$

Treatment of 1 a with concentrated sulfuric acid yielded two metal-free derivatives. As deduced by mass spectra and NMR, the major component ( $60 \%$ yield) is the free base furochlorophin (1 b). ${ }^{[9]}$ In the minor component (20\%) the furan ring has opened with the addition of $\mathrm{H}_{2} \mathrm{O}$ (most likely structure 7 or its tautomers). ${ }^{[10]}$ The structure of furochlorophin has been confirmed by X-ray diffraction (Fig. 2). ${ }^{[11]}$ The macrocycle is visibly more planar than the $\mathrm{Ni}$ complex due to the absence of the short-bond doming effect; the core size of $\mathbf{1} \mathbf{b}$ is also enlarged. This new macrocyclic ligand is easily converted into its $\mathrm{Cu}^{\mathrm{II}}, \mathrm{Zn}^{\mathrm{II}}$, as well as back to the $\mathrm{Ni}^{\text {II }}$ complex under mild conditions (metal acetate in $\mathrm{CHCl}_{3} / \mathrm{MeOH}$ ). The UV/VIS spectrum of the free base is shown in Figure 3. While the overall features are chlorin-like, there are two notable differences. First, the
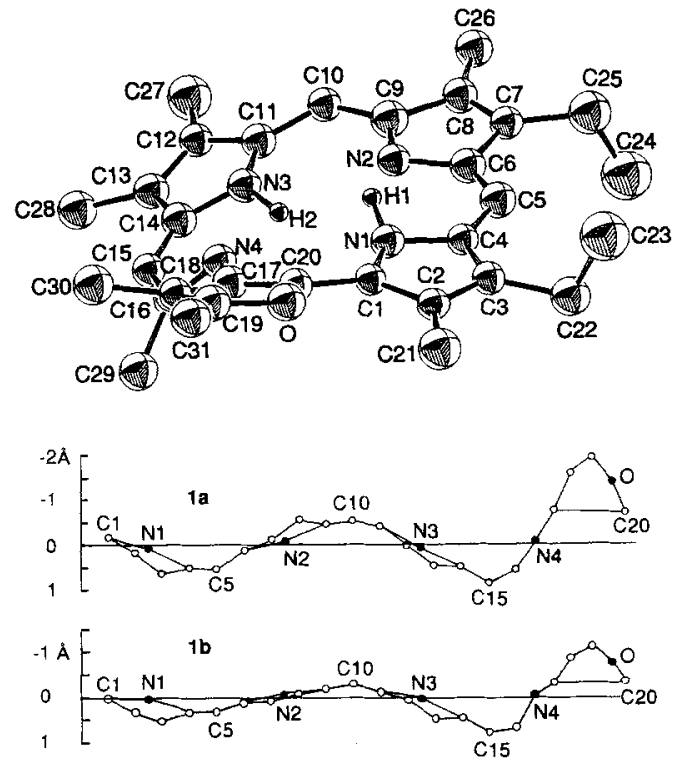

Fig. 2. Structure of $\mathbf{1} \mathbf{b}$ in the crystal. The deviation of the core atoms of $\mathbf{1} \mathbf{a}$ and $1 \mathrm{~b}$ from the nitrogen plane is shown by the cylindrical projection plots. The horizontal axis is not to scale.

Soret band as well as the long-wavelength band of $\mathbf{1 b}$ are significantly red shifted $(22 \mathrm{~nm}$ and $55 \mathrm{~nm}$, respectively, from those of a typical chlorin). Large bathochromic shifts

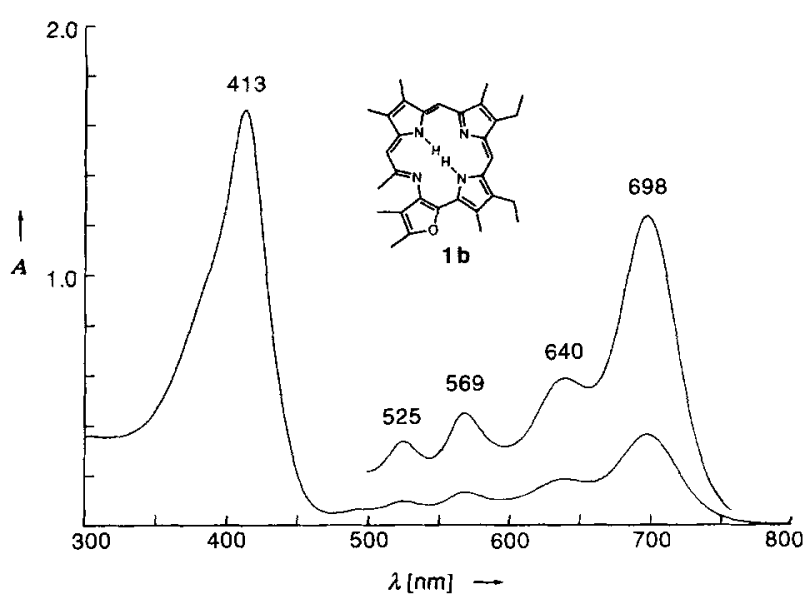

Fig. 3. UV/VIS spectrum of free base $1 \mathrm{~b}$ in $\mathrm{CH}_{2} \mathrm{Cl}_{2}, \mathrm{~A}=$ absorbance.

are also observed in the spectra of metal complexes $1 \mathbf{a}, 1 \mathbf{c}$, and $1 \mathbf{d}$ (Table 1). Second, the extinction coefficients of this series of compounds are relatively small (only about $1 / 3$ of those of corresponding chlorins). The bathochromic shift is probably brought about by an extension of the conjugation by the furan ring. The diminishing HOMO-LUMO gap is

Table 1. UV/VIS data $\left(\mathrm{CH}_{2} \mathrm{Cl}_{2}\right)$ for furochlorophin and its metal complexes.

\begin{tabular}{|c|c|c|c|c|c|}
\hline Compound & & $\lambda \max$ & (c) $\left[\mathrm{nm}\left(\mathrm{M}^{-}\right.\right.$ & $\left.\left.{ }^{1} \mathrm{~cm}^{-1}\right)\right]$ & \\
\hline $1 \mathrm{~b}(\mathrm{M}=2 \mathrm{H})$ & $413(60700)$ & $526(4900)$ & $569(5800)$ & $641(7200)$ & $699(13000)$ \\
\hline $\mathbf{1} \mathbf{a}(\mathrm{M}=\mathrm{Ni})$ & $422(41600)$ & $523(3800)$ & $580(4200)$ & & $685(18200)$ \\
\hline $1 \mathrm{c}(\mathrm{M}=\mathrm{Cu})$ & $\begin{array}{l}414(37200) \\
433(38700)\end{array}$ & $522(4600)$ & & & $682(11400)$ \\
\hline 1d $(M=Z n)$ & $440(50300)$ & $513(4500)$ & $583(2800)$ & $638(6300)$ & $683(11800)$ \\
\hline
\end{tabular}


also reflected in redox potentials. The furochlorophin $\mathbf{1 b}$ oxidizes to its $\pi$ cation radical at $0.47 \mathrm{~V}$ and reduces at $-1.25 \mathrm{~V}$ to the anion radical (determined by cyclic voltammetry, versus $\mathrm{Ag} / \mathrm{AgCl}$, in $\mathrm{CH}_{2} \mathrm{Cl}_{2}$ ). In comparison with

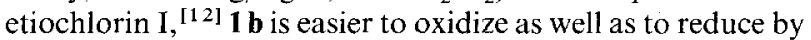
about $180 \mathrm{mV}$. This smaller redox span correlates well with the observed first absorption band shift. Although the absorption bands of the furochlorophin derivatives have lower extinction coefficients, their bandwidths are broader than those found in chlorins; thus the difference in total oscillator strength between the two systems is less drastic. The decrease in absorption extinction coefficient may be attributable to the reduced rigidity of a macrocycle missing some of the peripheral carbons. Previously Flitsch reported the synthesis of "isobacteriophin", which has two pyrrolic $\beta-\beta$ bonds removed; that chromophore also exhibits reduced absorption intensity as compared to isobacteriochlorins. ${ }^{[13]}$

To our knowledge $\mathbf{1} \mathbf{a}-\mathbf{1} \mathbf{d}$ are the first porphyrinoids that possess a chlorophin core structure. A previous attempt to prepare such compound was not successful. ${ }^{[14]}$ The inherent simplicity of this serendipitous synthesis not only enriches the chemistry of corrinoids ${ }^{[15]}$ but may have potential applications in the emerging photodynamic cancer therapy because of the desirable long-wavelength absorption characteristics of these pigments.

Received: August 21, 1991 [Z 4880 IE] German version: Angew. Chem. 1992, 104, 61

CAS Registry numbers:

1, 36544-38-4; 1 a, 137869-29-5; 1 b, 137869-28-4; 1 c, 137869-30-8; 1 d, 137869 $31-9 ; 2,14319-82-5 ; 7$ (tautomer 1). 137895-20-6; 7 (tautomer 2), 137895-21-7.

[1] a) R. Timkovich, M. S. Cork, R. B. Gennis, P. Y. Johnson, J. Am. Chem. Soc. 1985, 107, 6069-6075; b) C. Sotiriou, C. K. Chang, ibid. 1988, 110, $2264-2270$; c) J. T. Chiu, P. C. Lowen, I. Switala, R. B. Gennis, R. Timkovich, ibid. 1989, $111,7046-7051$.

[2] a) R. Grigg, A. W. Johnson, K. Richardson, K. W. Shelton, J. Chem. Soc. C 1969, 655-666; b) A. Hamilton, A. W. Johnson, ibid. 1971, 3879-3882.

[3] P. Iakovides, K. M. Smith, Tetrahedron Lett. 1990, 31, 3853-3856.

[4] $1 \mathrm{a}:{ }^{1} \mathrm{H}$ NMR (300 MHz, [D ] lacetone, TMS): $\delta=8.83,8.62,7.29$ (s. $1 \mathrm{H}$ each; $\mathrm{H}-5,10,15), 3.47$ (m, $4 \mathrm{H} ; \mathrm{Et}), 3.08,2.95,2.94,2.85,2.81,2.46 .2 .17$ (s. $3 \mathrm{H}$ each; Me), 1.53, 1.49 (t, $3 \mathrm{H}$ each; Et); ${ }^{13} \mathrm{C}$ NMR [D $]$ acetone: $\delta=148.18,146.63,146.58,146.26,145.21,141.92,141.73,139.51,139.35$ $137.80,137.27,136.94,136.36,134.54,134.25,132.22,128.01,113.03$, 105.16 (meso), 100.68 (meso), 95.07 (meso), 24.54, 24.48, 18.55, 16.63, $16.55,11.50,10.99,9.84,9.63,8.23$.

[5] $1 \mathrm{a}: \mathrm{C}_{34} \mathrm{H}_{34} \mathrm{~N}_{4} \mathrm{NiO}, M_{\mathrm{r}}=537.35$, monoclinic, space group $P 2 / c, a=$ $9.329(6), b=21.733(5), c=13.630(7) \AA, \beta=104.14(5)^{\prime}, V=2679.7(22) \AA^{3}$ $Z=4, \varrho_{\text {calcd }}=1.332 \mathrm{gcm}^{-3}, F(000)=1135.76, \lambda=0.70930 \AA, \mu\left(\mathrm{Mo}_{\mathrm{K} \alpha}\right)=$ $0.76 \mathrm{~mm}^{-1}$, crystal dimensions $0.03 \times 0.50 \times 0.60 \mathrm{~mm}$. A total of 3489 unique reflections and 2287 reflections with $[I>2.0 \sigma(I)]$ were collected on a Nonius diffractometer $(\theta / 2 \theta$ mode $)$ to $2 \theta<44.8^{\circ}$. Final model involved anisotropic refinement of all non-hydrogen atoms, $R=0.051\left(R_{\mathrm{w}}=\right.$ 0.053 ). Assignment of the $O$ atom was based on satisfactory temperature factors and $R$ value during relinement with $O$ at that position. See also [11 b].

[6] W. Flitsch, Pure \& Appl. Chem. 1986, 58, 153-160.

[7] A. Eschenmoser, Ann. N. Y. Acad. Sci. 1986, 471, 108-129.

[8] a) When a $\mathrm{CH}_{2} \mathrm{Cl}_{2}$ solution of 2. containing a few drops of triethylamine was allowed to stand in air for 4 days. $(8,12$-diethyl-1,2,3,7,17,18,19-octamethyl-5-oxooctadehydrocorrinato)nickel(II) was obtained in $15 \%$ yield. This structure was originally proposed by Johnson et al. [2 $\mathrm{b}$ ] and has been verified recently by X-ray crystal structure $[8 \mathrm{~b}]$. b) C. K. Chang. W. Wu, S.-S. Chern, G.-H. Lee, S.-M. Peng, Acta Crystallogr. submitted.

[9] 1 b: MS: $m / z 480\left(M^{+}\right),{ }^{1} \mathrm{H}$ NMR $\left(300 \mathrm{MHz}, \mathrm{CDCl}_{3}, \mathrm{TMS}\right): \delta=8.86$, 8.37, 7.33 ( $\mathrm{s}, 1 \mathrm{H}$ each; $\mathrm{H}-5,10,15), 3.62,3.49$ (q, $2 \mathrm{H}$ each; $\mathrm{Et}), 3.27,3.05$, $3.01,2.99,2.93,2.63,2.48$ (s, $3 \mathrm{H}$ each; Me groups), 2.08, 1.98 (br s. $1 \mathrm{H}$ each; NH) $1.60,1.57$ (t, $3 \mathrm{H}$ each; Et); ${ }^{13} \mathrm{C} \mathrm{NMR}\left(\mathrm{CDCl}_{3}\right): \delta=161.65$ $(\mathrm{C}-20), 154.46(\mathrm{C}-19), 143.75,143.45,143.07,139.85,139.52,139.09$. $136.35,134.92,132.68,131.38,130.07,128.25,123.35,113.92,104.73$ (meso), 98.29 (meso), 94.27 (meso), 25.43, 19.25, 18.94, 17.35, 17.15, 12.60, $12.11,10.90 .10 .83,10.78,10.63$. The two signals above $150 \mathrm{ppm}$, distinct in $\mathbf{1 b}$, were not observed in $\mathbf{1 a}$

[10] 7: MS: $m / z 498\left(M^{+}\right) .{ }^{1} \mathrm{H}$ NMR (300 MHz, CDCl 3. TMS): $\delta=11.29(\mathrm{~s}$, $1 \mathrm{H} ; \mathrm{OH}), 6.79,6.18,5.48$ (s, $1 \mathrm{H}$ each; $\mathrm{H}-5,10,15), 4.21$ (br s, $\geq 2 \mathrm{H} ; \mathrm{NH}$ ),
2.67, $2.66(\mathrm{q}, 2 \mathrm{H}$ each; Et) $2.26,2.23,2.13,2.12,1.99,1.84,1.71(\mathrm{~s}, 3 \mathrm{H}$ each; Me), 1.18, $1.16(t, 3 \mathrm{H}$ each; Et $)$. The ratio of $1 \mathbf{b} / 7$ could be increased by shortening the time $\mathbf{1}$ a was exposed to acid.

[11] a) 1 b (crystallized from $\mathrm{CH}_{2} \mathrm{Cl}_{2} /$ methanol): $\mathrm{C}_{31} \mathrm{H}_{36} \mathrm{~N}_{4} \mathrm{O}, M_{\mathrm{r}}=480.65$, monocinic, space group $P 2_{\mathrm{t}} / n, \quad a=13.859(9), \quad b=14.479(6), \quad c=$ $14.506(9) \AA, \quad \beta=116.940(5)^{\circ}, \quad V=2595(4) \AA^{3}, \quad Z=4, \quad \varrho_{\text {calcd }}=$ $1.230 \mathrm{gcm}^{-3}, F(000)=1032, \lambda=0.71069 \AA, \mu\left(\mathrm{Mo}_{\mathrm{K} \alpha}\right)=0.70 \mathrm{~cm}^{-1}$, crystal dimensions $0.06 \times 0.09 \times 0.14 \mathrm{~mm}$. A total of 2436 unique reflections and 933 reflections with $[l>3.0 \sigma(h)$ were collected on a Rigaku diffractometer using $\omega-2 \theta \operatorname{scan}$ mode $(2 \theta<40.1)$. Due to the low reflection/ parameter ratio, all non- $\mathrm{H}$ atoms were refined isotropically, including $\mathrm{H} 1$ and $\mathrm{H} 2$ which were located from the difference Fourier map. Final $R$ value is $0.102(R w=0.117)$. b) Further details of the crystal structure investigation are available on request from the Director of the Cambridge Crystallographic Data Center, University Chemical Laboratory, Lensfield Road. GB-Cambridge CB2 $1 \mathrm{EW}$ (UK), on quoting the full journal citation.

[12] C. K. Chang, J. Fajer, J. Am. Chem. Soc. 1980, 102, 848-850.

[13] W. Flitsch, D. Schulz, H.-G. Kneip, Liebigs Ann. Chem. 1985, 1004-1011.

[14] M. J. Crossley, L. G. King, J. Chem. Soc. Chem. Commun. 1984, 920-922.

[15] a) R. Grigg in The Porghyrins, Vol. 2, (Ed.: D. Dolphin), Academic Press. New York, 1978, Chapter 10; b) T. A. Melent eva, Usp. Khim. 1983, 52. 1136-1172; Russ. Chem. Rev. (Engl. Transl.) 1983, 52, 641-661.

\section{The Synthesis and Structure of an Unusual Uranium Pentachloride Derivative ${ }^{* *}$}

\author{
By Michael Wedler, Mathias Noltemeyer, \\ and Frank T. Edelmann*
}

\section{Dedicated to Professor Oskar Glemser on the occasion of his 80th birthday}

Uranium pentachloride $\left(\mathrm{UCl}_{5}\right)_{2}$ is a highly reactive compound which is reduced even by aliphatic hydrocarbons to uranium(Iv) complexes in a vigorous reaction. ${ }^{[1,2]}$ A selective exchange of one or more chlorine atoms has not yet been possible. We report here the unexpected formation of a uranium pentachloride derivative as well as its structural characterization.

According to investigations by Dehnicke et al., ${ }^{[3]}$ fully silylated benzamidines $\mathrm{RC}_{6} \mathrm{H}_{4} \mathrm{C}\left(=\mathrm{NSiMe}_{3}\right) \mathrm{N}\left(\mathrm{SiMe}_{3}\right)_{2}$ react with various metal halides with cleavage of $\mathrm{SiMe}_{3} \mathrm{X}$ ( $\mathrm{X}=$ halide) to give metal complexes with benzamidinato ligands $\mathrm{L}$. The reaction of benzamides $\mathrm{L}-\mathrm{SiMe}_{3}$ with $\mathrm{UCl}_{4}$

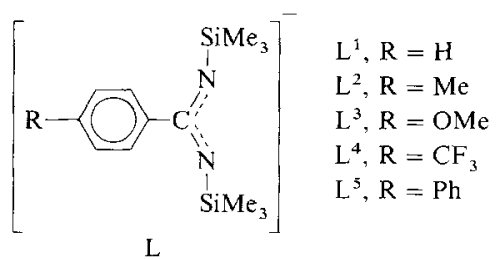

provides the green bis(benzamidinato)dichlorouranium(IV) complexes $\left[\mathrm{L}_{2} \mathrm{UCl}_{2}\right]$, which we have previously described. ${ }^{[4,5]}$ In addition, well-formed black single crystals were isolated from the reaction of $\mathrm{MeC}_{6} \mathrm{H}_{4} \mathrm{C}\left(==\mathrm{NSiMe}_{3}\right) \mathrm{N}$ $\left(\mathrm{SiMe}_{3}\right)_{2}$ with $\mathrm{UCl}_{4}$. This side product apparently arose from the unintentional introduction of air to the reaction mixture. This black compound could be obtained cleanly and reproduceably by controlled oxidation of the reaction

[*] Dr. F. T. Edelmann, Dr. M. Wedler, Dr. M. Noltemeyer Institut für Anorganische Chemie der Universität Tammannstrasse 4, D-W-3400 Göttingen (FRG)

$\left.{ }^{[* *}\right]$ We thank Prof. Dr. H. W. Roesky for his generous support. This research was funded by the Deutsche Forschungsgemeinschaft and the Fonds der Chemischen Industrie (habilitation fellowships for F. T. E.). 